Proceedings

\title{
The rights of people with lived experience of mental health problems during the pandemic: what we know and what we can learn for the future
}

\author{
Francisco José Eiroa-Orosa ${ }^{1}$ and ${ }^{2,3 *}$
}

\author{
1. Section of Personality, Assessment and Psychological Treatment, Department of Clinical Psychology \\ and Psychobiology, Faculty of Psychology, University of Barcelona, Barcelona, 08035, Catalonia, Spain; fei- \\ roa@ub.edu \\ 2. Yale Program for Recovery and Community Health, Department of Psychiatry, Yale School of Medicine, \\ Yale University, New Haven, CT, United States \\ 3. First-Person Research Group, Veus, Catalan Federation of 1st Person Mental Health Organisations, Bar- \\ celona, Catalonia, Spain; $\underline{\text { rdi@veus.cat }}$ \\ * Correspondence: fjeiroa@gmail.com or feiroa@ub.edu
}

Publisher's Note: MDPI stays neutral with regard to jurisdictional claims in published maps and institutional affiliations.

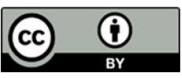

Copyright: $\odot 2020$ by the authors. Submitted for possible open access publication under the terms and conditions of the Creative Commons Attribution (CC BY) license (http://creativecommons.org/licenses/by/4.0/).

\begin{abstract}
The pandemic has dealt a severe blow to everyone, but especially to people with previous vulnerabilities, such as people with lived experience of mental health problems. Studies on the increased incidence of all types of mental disorders have been published incessantly since the beginning of the pandemic. However, not much has been said about the impact of the pandemic in terms of their rights, normally diminished by stigma and social discrimination. The full inclusion of people with lived experience of mental health problems as full citizens is a limitation in all societies, and it implies a burden in their recovery journeys. In these pandemic times we think the rights of persons with lived experience of mental health problems deserves special attention. In this presentation we will consider possible violations of rights that have occurred in the pandemic context but also samples of individual and collective resilience that have helped maintain well-being among this group of people.
\end{abstract}

Keywords: citizenship; COVID-19; discrimination; mental health; pandemic; recovery; stigma

\section{Introduction}

The current COVID-19 pandemic has become a global health crisis that has put many of the social, economic, and political world foundations on the ropes. In this context, people with previous experience of mental health problems are becoming one of the groups most severely affected. There is empirical evidence of an increase in anxious, depressive, obsessive, psychotic, and stress symptoms [1-3], in addition to increased alcohol consumption [4] and suicide rates among men [5] and violence against women [6]. All of these phenomena are even more intense in people diagnosed with severe mental disorders [7-9]. In general, vulnerable populations, those who barely survive in our increasingly competitive societies, have been affected by a total change in the societal game rules during the last months [10].

People diagnosed with severe mental disorders are subjected not only to stigmatization outside and within the mental health care system [11], but also to constant violations of their human rights [12]. Some examples are involuntary inpatient and outpatient treatments, forced medication, overmedication, electroconvulsive therapy under duress, mechanical restraints, seclusion, isolation, and arbitrary legal incapacitations and guardianships. The underlying beliefs that enable this degrading treatment appear to be formed by a lack of awareness of mental health professionals' prejudices [13]. This causes many 
people affected by psychosocial hardships to be forced to hide their suffering preventing early detection and adequate therapeutic interventions [14]. We could say that, in general, people with psychosocial impairments are not entirely considered full citizens.

The citizenship framework is an emerging trend in the field of mental health and social inclusion. Citizenship has been for centuries a complex social concept concerning the degree to which a person is a part of and can influence society $[15,16]$. Lately, it has also become the leitmotiv of a professional and academic movement that, in a similar way to the recovery movement, which has had wide impact on the transformation of services and systems addressed to people with mental health problems [17], tries to improve the living conditions of people with psychosocial impairments by fully exercising their rights [18]. Although both movements share values and objectives, citizenship explicitly emphasizes social-contextual dimensions such as the importance of social justice and advocacy $[19,20]$. This might have been eclipsed within the Recovery movement by having become mainstream, as well as by mixing elements of personal and clinical recovery [21,22]. From a 'therapeutic objectives' point of view, in the same way that the Recovery movement proposed to change the focus from the reduction of symptoms to the autonomous construction of a life project in community even with possible limitations [23], the citizenship movement would add a 'rights' component. That is to say, in order to be able to build a life project in a truly autonomous way, one has to be aware and be able to make use of the 5 Rs proposed by Rowe and colleagues: rights, responsibilities, roles, resources and relationships $[15,18,24,25]$. As can be inferred, these capital dimensions of our personhood have been affected during the pandemic throughout the population, but probably in a more incisive way among people diagnosed with mental disorders.

This presentation intends to explore the impact of the COVID-19 pandemic from the perspective of the citizenship of the people diagnosed with mental health problems. This will be performed by means of the analysis of two focus groups carried out with mental health experts including mental health activists and peer support specialists.

\section{Materials and Methods}

We carried out two focus groups with 17 key participants from two Spanish-speaking countries: Spain, and Colombia. Participants included mental health professionals including peer support workers, policy makers, health managers, anti-stigma campaigns technicians and mental health activists. The focus groups aimed at deepening on how the key concepts of recovery, personhood and citizenship are understood within the context and challenges that COVID-19 presents to us all.

There were four conversation blocks based in the following questions:

1. In mental health, the concept of recovery can mean different journeys for different people aimed at reclaiming or developing a new sense of self and living up to one's own aspirations. How is recovery in mental health experienced in your region?

2. Citizenship is bestowed to people by the nation state, by birth or by naturalization. It is both a legal status and a social practice. Citizenship affords the citizen with a bundle of rights and responsibilities, inclusion, and a sense of belonging to their co-citizens and the country. How is citizenship experienced in your country or region?

3. Personhood can be described as an identity, and recognition of that identity by others, thereby affording us the same respect as others expect and to be a full and active participant in society. It can involve seeing beyond a particular label or category to see a person with strengths or attributes. How is personhood understood in your region?

4. How has COVID-19 impacted people's experiences of recovery, citizenship and personhood in your country or region? What action or actions are needed to promote access? Are there any barriers that need to be overcome?

\section{Results}

\subsection{Recovery}

Participants consider recovery to be a polysemic term linked to empowerment and resilience. It involves a shift from classic biomedical views based on symptoms still very 
present in mainstream care. It has its roots in the rehabilitation movement but has gone beyond, influencing different settings and professional thought. There is a consensus on the need for the participation of affected people and their families. However, sometimes it is problematic as can be linked to productivity and normality instead. Besides, some survivors sometimes say they do not want to 'recover' their former life, as it was not full of meaning at all. Additionally, some relatives sometimes say that it is a model designed for those who can recover, there are other affected people who might need intense support that they say it is not fully acknowledged by this framework. In general, the group showed that In the Spanish-speaking context there is a general understanding of the concepts generated by the North American Recovery movement.

\subsection{Citizenship}

The debate on citizenship in the was influenced by mental health concepts as it was discussed after recovery. There was a consensus that people with mental health problems are denied a part of their citizenship. It can be considered an important concept for mental health and social professionals because there are people who are denied citizenship even though it is supposed to be innate. There was a specific debate on migrants as they must meet requirements to acquire it. There was also a reflection on whether to be a citizen one must participate in some kind of activity or is something independent of what we do. There was some consensus that it is very difficult to feel like a citizen one does not participate in society. Finally, it was stressed that there is a crisis of values in today's society that affects the citizenship status of many people.

\subsection{Personhood}

This concept introduced the discussion of the role that humanity as a collective play in the mental health of individuals. For some participants who happened to be mental health professionals the concept of person can be better understood than citizenship. Other said that sometimes not to recognizing the other is needed to constitute oneself. Denying the other's personality allows some to build themselves. In general participants found it an interesting concept because if a person with a mental health problem feels like a 'person', there are things related to coercion that cannot be done. Finally, it was stressed that people with mental health problems often do not consider themselves people because parts of their socially recognized identity (profession, possessions...) are missing.

\subsection{Recovery, citizenship, and personhood during the Covid-19 among people with psychosocial impairments}

Participants coincided that there were a lot of contradictions in the field of mental health services within the pandemic period. There were a lot of tensions on the table as many decisions had to be made very quickly to meet the needs of people with mental health problems during the lockdown. There was a lot of improvisation, but many good things came out of the way it was managed, such as the ways in which contact between practitioners and service users was maintained, or how users of certain services were able to continue in treatment.

Some agreed that the best and worst of people have come out. On the good side, it can be said that many crisis situations were faced in a more collective way than is usually adopted, finding multiple allies who were stimulated by an atmosphere of solidarity. For instance, regarding homeless people, there was suddenly accommodation for everyone. But that also makes us wonder why this was not the case before the pandemic, why we had to wait for such a crisis to remember homeless people. There were controversies arising from the inpatients permits to leave. In some places it was managed very well, but other were very restrictive and there were people who could not leave for a long time, which negatively affected them. In addition there was a paradoxical effect since many people, including mental health professionals, have understood that being locked up is bad for mental health, so maybe it cannot be considered a treatment. There was also the 
case of people with diverse relational patterns who could finally stay home without having to justify themselves.

However, on the downside, the digital divide is wreaking havoc. Although the technification of care has made it easier for many to receive psychosocial support, those who do not have access due to lack of knowledge or due to financial difficulties are being left behind. On the other hand, on the side of the most excluded we can find people with increased difficulties during the pandemic. For instance, people that live in very little spaces as whole families sharing a single room, faced very complicated living situations.

\section{Discussion}

In this work we have analyzed the contents of two focus groups using a framework based on Rowe's [16] citizenship framework which tried to deepen on the concepts of recovery, citizenship, and personhood during the Covid-19 pandemic among people with psychosocial impairments. We have been able to see how experts understand these concepts and how they have been affected during the pandemic. Despite some positive aspects and the awareness that all of us have had that confinement and loneliness cause distress, it is clear that the pandemic jeopardizes the lives of many people and, at the same time, their support systems. We should not ignore the many voices warning that the consequences of the pandemic at the psychosocial level will extend for years [10].

\section{Conclusions}

Although there has been a large amount of research on mental health symptomatology during the pandemic, respect for the rights and consideration as full citizens of people with psychosocial impairments is an unexplored topic. With this work we have tried to take a first step in this direction. We have seen that the pandemic is both an opportunity and a challenge for this collective. We must continue trying to analyze the reality of the people with mental health problems from this perspective of rights and not only of illbeing, to promote their empowerment and autonomy.

Funding: FJEO has received funding from the Spanish Ministry of Science and Innovation under the Ramón y Cajal Grant Agreement N RYC2018-023850-I.

\section{References}

1. Brown, E.; Gray, R.; Lo Monaco, S.; O’Donoghue, B.; Nelson, B.; Thompson, A.; Francey, S.; McGorry, P. The potential impact of COVID-19 on psychosis: A rapid review of contemporary epidemic and pandemic research. Schizophr. Res. 2020, 222, 79-87, doi:10.1016/j.schres.2020.05.005.

2. Davide, P.; Andrea, P.; Martina, O.; Andrea, E.; Davide, D.; Mario, A. The impact of the COVID-19 pandemic on patients with OCD: Effects of contamination symptoms and remission state before the quarantine in a preliminary naturalistic study. Psychiatry Res. 2020, 291, 113213, doi:10.1016/j.psychres.2020.113213.

3. Ozamiz-Etxebarria, N.; Idoiaga Mondragon, N.; Dosil Santamaría, M.; Picaza Gorrotxategi, M. Psychological Symptoms During the Two Stages of Lockdown in Response to the COVID-19 Outbreak: An Investigation in a Sample of Citizens in Northern Spain. Front. Psychol. 2020, 11, 1-9, doi:10.3389/fpsyg.2020.01491.

4. Da, B.L.; Im, G.Y.; Schiano, T.D. Coronavirus Disease 2019 Hangover: A Rising Tide of Alcohol Use Disorder and AlcoholAssociated Liver Disease. Hepatology 2020, 72, 1102-1108, doi:10.1002/hep.31307.

5. Khan, A.R.; Ratele, K.; Arendse, N. Men, Suicide, and Covid-19: Critical Masculinity Analyses and Interventions. Postdigital Sci. Educ. 2020, 651-656, doi:10.1007/s42438-020-00152-1.

6. Ravindran, S.; Shah, M. Unintended Consequences of Lockdowns: COVID-19 and the Shadow Pandemic. NBER Work. Pap. 2020, 27562.

7. González-Blanco, L.; Dal Santo, F.; García-Álvarez, L.; de la Fuente-Tomás, L.; Moya Lacasa, C.; Paniagua, G.; Sáiz, P.A.; GarcíaPortilla, M.P.; Bobes, J. COVID-19 lockdown in people with severe mental disorders in Spain: Do they have a specific psychological reaction compared with other mental disorders and healthy controls? Schizophr. Res. 2020, 223, 192-198, doi:10.1016/j.schres.2020.07.018.

8. Sukut, O.; Ayhan Balik, C.H. The impact of COVID-19 pandemic on people with severe mental illness. Perspect. Psychiatr. Care 2020, ppc.12618, doi:10.1111/ppc.12618.

9. Yao, H.; Chen, J.H.; Xu, Y.F. Patients with mental health disorders in the COVID-19 epidemic. The Lancet Psychiatry 2020, 7, e21, doi:10.1016/S2215-0366(20)30090-0.

10. Otu, A.; Charles, C.H.; Yaya, S. Mental health and psychosocial well-being during the COVID-19 pandemic: The invisible elephant in the room. Int. J. Ment. Health Syst. 2020, 14, 1-5, doi:10.1186/s13033-020-00371-w. 
11. Henderson, C.; Noblett, J.; Parke, H.; Clement, S.; Caffrey, A.; Gale-Grant, O.; Schulze, B.; Druss, B.; Thornicroft, G. Mental health-related stigma in health care and mental health-care settings. The Lancet Psychiatry 2014, 1, 467-482, doi:10.1016/S22150366(14)00023-6.

12. Mfoafo-M'Carthy, M.; Huls, S. Human Rights Violations and Mental Illness. SAGE Open 2014, 4, 215824401452620, doi:10.1177/2158244014526209.

13. Knaak, S.; Mantler, E.; Szeto, A. Mental illness-related stigma in healthcare. Healthc. Manag. Forum 2017, 30, 111-116, doi:10.1177/0840470416679413.

14. Corrigan, P.W. How stigma interferes with mental health care. Am. Psychol. 2004, 59, 614-625, doi:10.1037/0003-066X.59.7.614.

15. Rowe, M.; Kloos, B.; Chinman, M.; Davidson, L.; Cross, A.B. Homelessness, Mental Illness and Citizenship. Soc. Policy Adm. 2001, 35, 14-31, doi:10.1111/1467-9515.00217.

16. Rowe, M. Citizenship and Mental Health; Oxford University Press: New York, 2015; ISBN 978-0-19-935538-9.

17. Pelletier, J.-F.; Corbière, M.; Lecomte, T.; Briand, C.; Corrigan, P.; Davidson, L.; Rowe, M. Citizenship and recovery: two intertwined concepts for civic-recovery. BMC Psychiatry 2015, 15, 37, doi:10.1186/s12888-015-0420-2.

18. Rowe, M.; Benedict, P.; Sells, D.; Dinzeo, T.; Garvin, C.; Schwab, L.; Baranoski, M.; Girard, V.; Bellamy, C. Citizenship, Community, and Recovery: A Group- and Peer-Based Intervention for Persons With Co-Occurring Disorders and Criminal Justice Histories. J. Groups Addict. Recover. 2009, 4, 224-244, doi:10.1080/15560350903340874.

19. Rowe, M.; Davidson, L. Recovering Citizenship. Isr. J. Psychiatry Relat. Sci. 2016, 53, 14-20.

20. Ponce, A.N.; Rowe, M. Citizenship and Community Mental Health Care. Am. J. Community Psychol. 2018, 61, 22-31, doi:10.1002/ajcp.12218.

21. Leamy, M.; Bird, V.; Le Boutillier, C.; Williams, J.; Slade, M. Conceptual framework for personal recovery in mental health: Systematic review and narrative synthesis. Br. J. Psychiatry 2011, 199, 445-452, doi:10.1192/bjp.bp.110.083733.

22. Andresen, R.; Caputi, P.; Oades, L.G. Do clinical outcome measures assess consumer-defined recovery? Psychiatry Res. 2010, 177, 309-317, doi:10.1016/j.psychres.2010.02.013.

23. Anthony, W.A. Recovery from mental illness: The guiding vision of the mental health service system in the 1990s. Psychosoc. Rehabil. J. 1993, 16, 11-23, doi:10.1037/h0095655.

24. Rowe, M. Crossing the Border: Encounters between Homeless People and Outreach Workers; University of California Press: Berkeley, CA, 1999;

25. Rowe, M.; Pelletier, J.-F. Citizenship: A Response to the Marginalization of People with Mental Illnesses. J. Forensic Psychol. Pract. 2012, 12, 366-381, doi:10.1080/15228932.2012.697423. 